\title{
Perancangan Aplikasi Chatting Berbasis Web di PT. Pura Barutama Kudus Menggunakan Socket.IO dan Framezork Foundation
}

\author{
Ramos Somya* \\ Program Studi S1 Teknik Informatika, Fakultas Teknologi Informasi \\ Universitas Kristen Satya Wacana \\ Salatiga \\ *ramos.somya@uksw.edu
}

\begin{abstract}
Abstrak-Aplikasi chatting merupakan aplikasi yang penting pada sebuah perusahaan besar karena dapat dipastikan antara divisi satu dengan divisi yang lain berada di lokasi yang berjauhan. EDP Keuangan PT. Pura Barutama Kudus bertugas dalam pembuatan program aplikasi yang terkait dengan pengolahan data keuangan dan faktur di semua unit di PT. Pura Barutama. Aplikasi keuangan yang telah ada akan selalu berkembang sesuai dengan kebutuhan user. Kendala yang dihadapi adalah aktivitas komunikasi dan penyebaran informasi pada PT. Pura Barutama dilakukan dengan menggunakan layanan email maupun aplikasi messenger. Untuk menggunakan layanan tersebut, perangkat yang digunakan harus selalu terkoneksi dengan internet. Apabila internet mati maka komunikasi tidak dapat dilakukan. Jalan satu-satunya untuk menyebarkan informasi adalah dengan menelepon satu per satu ke tiap-tiap unit. Hal ini menimbulkan ketidakefisienan pekerjaan dan produktivitas perusahaan menjadi terganggu. Pada penelitian ini dilakukan perancangan aplikasi chatting dengan menggunakan Framework. CodeIgniter, Socket.IO dan Framework. Foundation untuk mengatasi masalah yang ada. Hasil dari penelitian ini adalah aplikasi chatting berbasis web yang dibangun menggunakan Framework CodeIgniter, Socket.IO dan Framework. Foundation terbukti dapat membantu user untuk saling berkomunikasi atau melakukan attach file, serta mempermudah melakukan penyebaran informasi atau pengumuman baik dalam kondisi terhubung internet maupun tidak.
\end{abstract}

Kata Kunci: Aplikasi Chatting, Web, Socket.IO, Framework Foundation, Framework CodeIgniter

\section{Pendahuluan}

Aplikasi chatting merupakan aplikasi yang penting pada sebuah perusahaan besar karena dapat dipastikan antara divisi satu dan divisi yang lainnya berada di tempat yang berjauhan. Divisi keuangan PT. Pura Barutama selalu mengontrol dan berkomunikasi dengan seluruh unit yang ada di PT. Pura Barutama. Penggunaan aplikasi chatting akan meningkatkan produktivitas dan efisiensi kerja. Misalnya sebagai sarana berkomunikasi, attach file dan sebagai media pengumuman.

EDP Keuangan adalah salah satu sub divisi dari divisi keuangan di PT. Pura Barutama selalu beinteraksi dengan berbagai macam divisi yang ada. Selain itu EDP Keuangan bertugas dalam pembuatan program yang terkait dengan pengolahan data keuangan, faktur di semua unit PT. Pura Barutama. Aplikasi keuangan yang telah ada akan selalu berkembang sesuai kebutuhan user.

Aktivitas komunikasi dan penyebaran informasi pada PT. Pura Barutama dilakukan dengan menggunakan layanan emailmaupun aplikasi messenger, untuk menggunakan layanan tersebut, perangkat yang digunakan harus selalu terkoneksi dengan internet. Apabila internet mati maka komunikasi tidak dapat dilakukan. Jalan satu-satunya untuk menyebarkan informasi adalah dengan menelepon satu per satu ke tiap-tiap unit. Hal ini menimbulkan ketidakefisienan pekerjaan dan produktivitas menjadi terganggu.

Berdasarkan permasalahan tersebut, maka dapat diketahui rumusan masalah dalam penelitian ini adalah bagaimana membuat aplikasi chatting berbasis web menggunakan Framework CodeIgniter, Socket.IO dan Framework Foundation dengan memanfaatkan jaringan komputer lokal yang ada di PT. Pura Barutama. Aplikasi chatting tersebut hanya membutuhkan sebuah browser yang digunakan untuk mengakses aplikasi chatting selama perangkat terkoneksi dengan jaringan lokal baik menggunakan kabel maupun wireless tanpa terkoneksi dengan internet. Selain itu, aplikasi berbasis web tergolong ringan, sehingga spesifikasi komputer yang digunakan oleh user tidak berat.

Aplikasi chatting dibangun menggunakan Framework CodeIgniter (CI) dan Socket.IO sebagai back-end. Framework CodeIgniter mendukung konsep Model View Controller (MVC) sehingga dalam pengembangan aplikasi chatting akan menjadi lebih terstruktur dan terorganisasi. Sedangkan untuk interface (front-end) aplikasi chatting menggunakan Framework Foundation untuk membuat aplikasi chatting ini menjadi responsive dan untuk penyimpanan data menggunakan database Oracle karena menyesuaikan dengan database yang digunakan PT. Pura Barutama. 
Mengingat begitu luasnya ruang lingkup pembuatan aplikasi chatting dan terbatasnya kemampuan dan identifikasi maka diperlukan batasan agar sistem yang dibangun tidak menyimpang dari permasalahan dalam sistem aplikasi chatting. Adapun batasan masalah yang dilakukan adalah aplikasi hanya dapat dipergunakan untuk perorangan (Private Chat), dikarenakan aplikasi chatting ini bersifat rahasia. Selain digunakan untuk melakukan private chat, aplikasi ini juga dapat memberikan informasi berupa pengumuman kepada user maupun unit yang lain apabila ada pembaruan aplikasi yang dibuat oleh EDP Keuangan PT. Pura Barutama.

Diharapkan dengan dibangunnya aplikasi ini, dapat mempermudah para penggunanya untuk berkomunikasi dan bertukar informasi. Sehingga dapat meningkatkan produktivitas kerja dan mengefisienkan waktu

\section{Kajian Pustaka}

\section{a. Penelitian Terdahulu}

Terdapat beberapa penelitian terdahulu yang digunakan sebagai acuan dalam penelitian ini. Penelitian pertama menghasilkan aplikasi yang dapat melakukan pembuatan suatu room yang dapat dilakukan oleh semua pengguna baik itu pengguna telepon seluler maupun pengguna komputer. Apabila melakukan mengirim dengan ukuran file yang besar maka proses pengiriman akan menjadi lama [1].

Penelitian kedua menghasilkan aplikasi yang dibangun dengan menggunakan Visual Basic 6.0. Aplikasi yang dilengkapi dengan menu send file untuk mengirimkan text yang mempermudah komunikasi antar pengguna yang berada dalam sebuah jaringan. Aplikasi chatting yang dikembangkan tidak adanya pemisahan form antara private dengan group. Model pengiriman text melalui menu send file harus memasukkan alamat IP tujuan pengguna sehingga dinilai tidak efektif dan efisien. Program aplikasi hanya dapat berjalan pada sistem operasi Windows [2].

Penelitian ketiga mengimplementasi Algoritma Rijndeal 128 pada aplikasi chatting berbasis HTML5 webSocket. Pada penelitian tersebut menghasilkan aplikasi group chatting. Pesan yang dikirim akan dienkripsi dengan menggunakan algoritma Rijndeal 128, sehingga pesan menjadi aman [3].

Berdasarkan penelitian yang telah dilakukan sebelumnya yang menjadi pembeda antara penelitian ini dan penelitian terdahulu adalah aplikasi chatting dibuat dengan menggunakan Framework CodeIgniter, Socket. IO dan Framework Foundation. Penggunaan Framework CodeIgniter penulisan kode akan menjadi terstruktur dan terorganisir karena Framework CodeIgniter menerapkan konsep MVC (Model View Controller). Socket.IO memungkinkan pembuatan aplikasi komunikasi realtime antara client dan server. Penggunaan Framework. Foundation membuat halaman web menjadi responsive sehingga dapat menyesuaikan di perangkat manapun saat aplikasi diakses.

\section{b. Chatting}

Chatting adalah pecakapan dua orang atau lebih secara real time melalui komputer yang terhubung dengan jaringan. Layanan untuk chatting di internet antara lain Yahoo, Skype, mIRC, Windows Live Messenger. Adanya layanan chat memungkinkan untuk dapat berkomunikasi melalui internet dengan orang-orang yang berada di seluruh dunia [4].

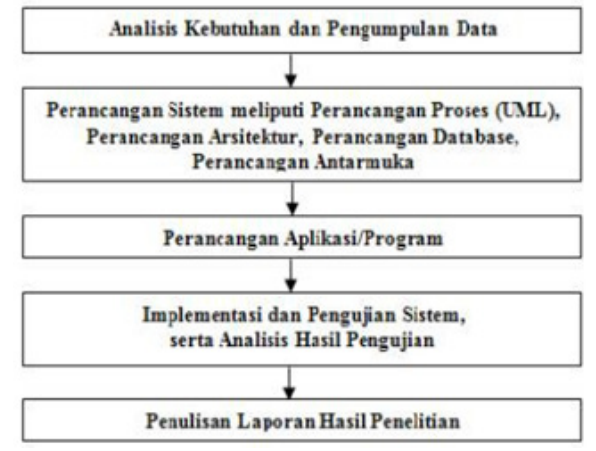

Gambar 1. Tahapan Penelitian

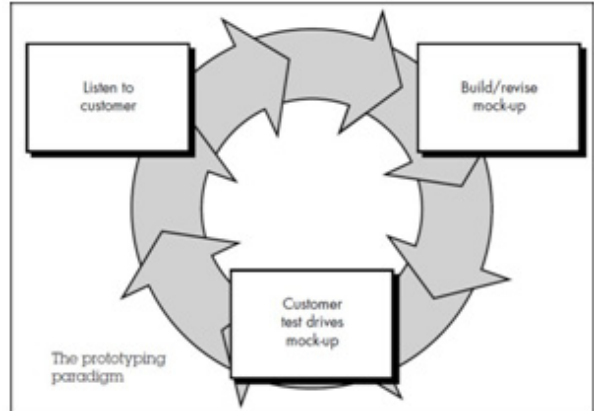

Gambar 2. Model prototyping [10]

\section{c. Framework}

Framework adalah kumpulan perintah atau fungsi dasar yang membentuk aturan-aturan tertentu dan saling berinteraksi satu sama lain sehingga dalam pembuatan aplikasi website, programmer harus mengikuti aturan dari framework tersebut. CodeIgniter dilengkapi dengan berbagai pustaka siap pakai untuk berbagai kebutuhan. Misalnya saja koneksi database, email, session dan cookies, keamanan, manipulasi gambar dan banyak lagi sehingga mempermudah pekerjaan [5].

\section{d. Socket.IO}

Socket.IO adalah lapisan komunikasi berbasis event untuk aplikasi web realtime, yang dibangun di atas Engine. IO. Hal ini memungkinkan pengembang untuk mengirim dan menerima data tanpa khawatir tentang kompatibilitas browser yang berbeda [6].

\section{e. Framework Foundation}

Framework Foundation adalah framework yang dibangun dengan HTML, CSS, dan Javascript, sebagai komponen utama dari web. Framework Foundation mengunakan teknologi JQuery, HTML 5 dan Normalizer [7]. Framework Foundation digunakan untuk membuat web dapat menyesuaikan resolusi layar yang digunakan.

\section{f. Basis Data Oracle}

Oracle adalah sistem basis data yang memiliki banyak fitur yang memungkinkan administrator basis data dapat mengelola data secara lebih akurat sehingga Oracle lebih sesuai digunakan sebagai sistem basis data untuk aplikasi yang berkuran besar dan kompleks [8]. 


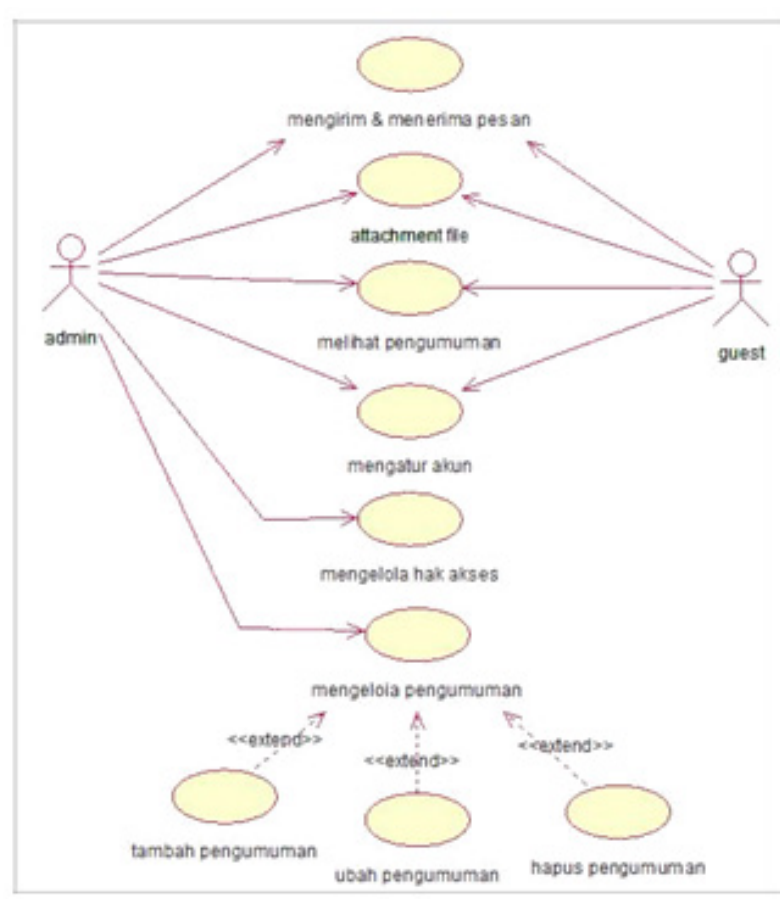

Gambar 3. Diagram Use Case

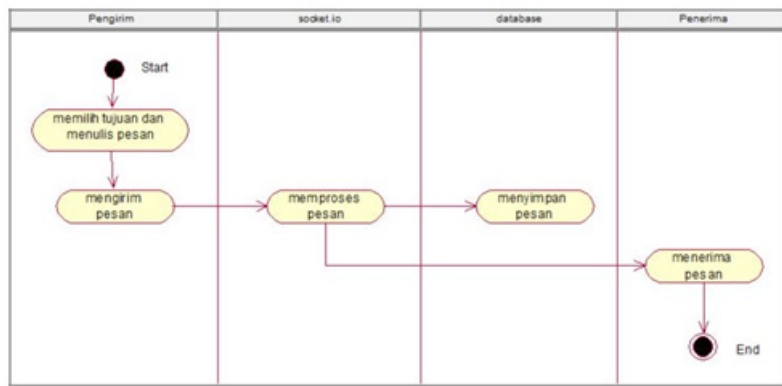

Gambar 4. Diagram Activity Mengirim Pesan

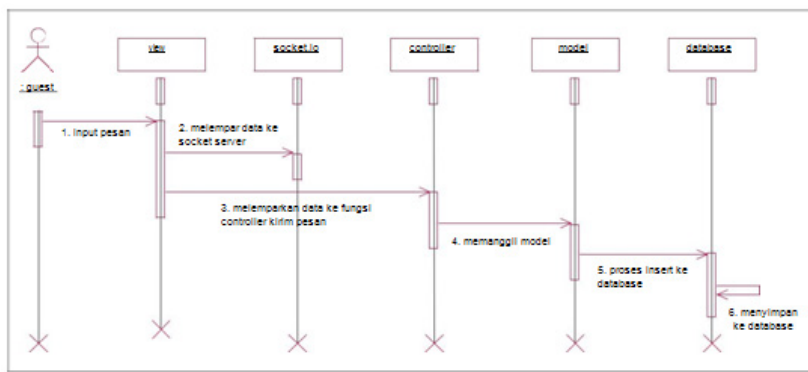

Gambar 5. Diagram Sequence Proses Kirim Pesan

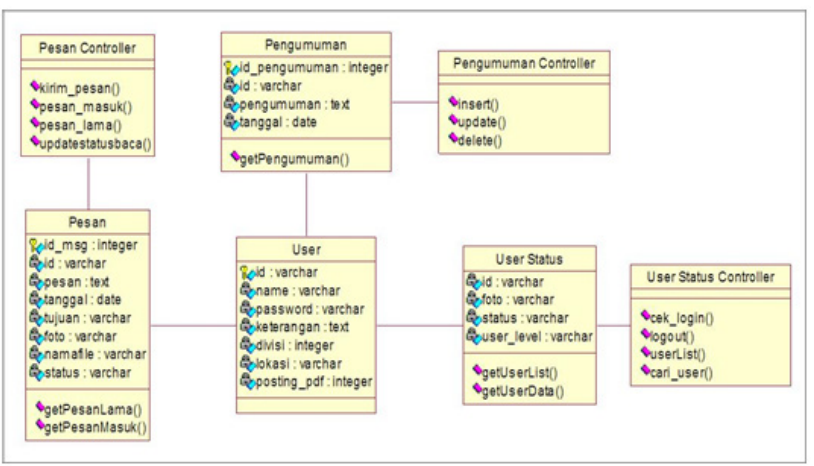

Gambar 6. Diagram Class

\section{Perancangan Sistem}

Pada penelitian ini dilakukan beberapa tahapan yang saling berkaitan dengan tahapan selanjutnya, yaitu: 1) Analisis kebutuhan dan pengumpulan data yang diperlukan. 2) Perancangan sistem. 3) Perancangan aplikasi/program. 4) Implementasi dan pengujian sistem, serta analisis hasil pengujian. 5) Penulisan laporan hasil penelitian [9]. Tahapan-tahapan yang dilakukan dalam penelitian ini dapat dilihat pada Gambar 1.

Berdasarkan Gambar 1 dapat dijelaskan tahapan penelitian yang dilakukan adalah sebagai berikut: 1) Tahapan pertama: analisis dan pengumpulan data, di mana peneliti melakukan wawancara dengan karyawan EDP Keuangan tentang aplikasi yang akan dibuat. Berdasarkan hasil wawancara dengan karyawan EDP Keuangan bahwa selama ini belum ada media yang menghubungkan unit satu ke unit yang lainnya dalam menyebarkan informasi atau attach file tanpa menggunakan internet. Selama ini hanya menggunakan telepon dan email untuk berkomunikasi. Email sendiri memiliki kekurangan yaitu membutuhkan koneksi internet. Jika koneksi internet mati, maka tidak bisa terjadi komunikasi. Jika melalui telepon akan terasa tidak efisien karena karyawan EDP Keuangan harus menghubungi satu per satu unit yang banyak di PT. Pura Barutama jika terjadi perubahan program. Sehingga dibutuhkan aplikasi yang dapat menyediakan fasilitas chatting, attach file, dan penyebaran pengumuman dengan memanfaatkan jaringan lokal. Tahap kedua, ketiga, dan keempat dilakukan perancangan aplikasi chatting menggunakan metode Prototype. Sedangkan tahap kelima dilakukan penulisan artikel ilmiah atau laporan penelitian.

Metode perancangan yang dipakai dalam pembuatan aplikasi chatting adalah metode Prototyping. Metode Prototyping adalah metode dalam pengembangan rekayasa software yang bertahap dan berulang serta mementingkan sisi user sistem. Penggunaan metode Prototyping, pengembang dan karyawan EDP Keuangan dapat saling berinteraksi selama proses pembuatan sistem sampai aplikasi sesuai dengan kebutuhan pengguna.

Tahap pengumpulan kebutuhan dilakukan untuk mengetahui permasalahan dan kebutuhan sistem. Pada tahap ini juga dilakukan pencarian data yang dibutuhkan oleh sistem. Agar aplikasi chatting yang dibagun dapat memenuhi kebutuhan pengguna. Analisis kebutuhan sistem dilakukan bersama dengan karyawan EDP Keuangan. Berdasarkan analisis kebutuhan sistem yang dilakukan bahwa selain untuk melakukan chatting dengan user lain, dibutuhkan juga fasilitas untuk attach file, dan melakukan pengumuman. Pada aplikasi chatting yang dibangun dibagi menjadi dua hak akses yaitu administrator dan user biasa. Kebutuhan adminstrator mencakup: chatting dengan pengguna lain dengan fasilitas attach file, posting pengumuman, hapus pengumuman, mengubah pengumuman jika terjadi kesalahan, mengelola user, mengelola user di sini maksudnya adalah memberikan hak akses administrator kepada user biasa jika user tersebut ini memposting pengumuman. Sedangkan kebutuhan user biasa hanya melakukan chatting dengan pengguna lain dengan fasilitas attach file. Data user sendiri menggunakan data yang sudah dimiliki oleh PT Pura Barutama, sehingga pada aplikasi chatting ini tidak perlu menambahkan data user baru, karena diambil dari database yang sudah ada. 
Analisis kebutuhan hardware dan spesifikasi software yang digunakan dalam membangun aplikasi chatting ini yaitu: analisis perangkat keras yang akan digunakan adalah Prosesor Intel Core i3, $2.3 \mathrm{GHz}$, RAM 6 GB dan Harddisk 500 GB. Sedangkan perangkat lunak yang digunakan adalah sistem Operasi Windows 7 Ultimate, Sublime sebagai text editor, web server (Apache), web browser (dalam penelitian ini menggunakan Google Chrome), Oracle sebagai database, dan Rational Rose untuk membuat UML diagram sistem.

Sebelum dilakukan pengkodean, dilakukan perancangan UML diagram untuk memvisualisasikan alur proses dan kebutuhan data. UML dibuat dalam diagram Use Case, diagram Activity, diagram Sequence dan diagram Class yang akan dijelaskan satu per satu.

Gambar 3 menunjukkan diagram Use Case dari aplikasi chatting. Aplikasi yang dibuat dibedakan menjadi dua jenis user yaitu administrator dan guest (user biasa). Aktor dengan hak akses admin dapat mengirimkan dan menerima pesan, attach file, melihat pengumuman, mengelola data user dengan memberikan hak akses administrator kepada user biasa, memposting pengumuman, menghapus pengumuman, mengubah pengumuman jika terjadi kesalahan. Sedangkan aktor dengan hak akses guest (user biasa) hanya dapat mengirimkan dan menerima pesan, attach file, melihat pengumuman, dan mengatur akunnya sendiri.

Gambar 4 menunjukkan diagram Activity ketika pengirim mengirimkan pesan. Hal pertama yang dilakukan adalah pengirim menentukan tujuan dan pesan yang akan dikirim. Kemudian data yang sudah diinputkan akan diproses melalui Socket kemudian ditampilkan pada panerima. Data pesan yang dikirim akan disimpan ke dalam database, sehingga histori percakapan masih bisa dilihat.

Gambar 5 merupakan diagram Sequence dari proses pengiriman pesan. Pertama user menginputkan pesan pada halaman view. Kemudian data diproses oleh server socket dan data menjadi parameter di controller kirim pesan. Setelah itu controller akan memanggil fungsi pada model dengan parameter yang dikirimkan controller kemudian model akan berhubungan dengan database untuk menyimpan data.

Gambar 6 merupakan diagram Class dari aplikasi chatting yang menunjukkan model dan controller. Pada aplikasi chatting dibuat dalam 4 model class yaitu user class, user status class, pesan class dan pengumuman class. Model class ini yang nantinya akan berhubungan dengan database. Sedangkan controller class akan menghubungkan antara view dan model class. Pada aplikasi chatting dibuat dalam 3 controller class yaitu user status controller, pesan controller, dan pengumuman controller.

Perulangan dari proses pada metode Prototyping terus berlangsung hingga semua kebutuhan terpenuhi. Proses evaluasi dilakukan sebanyak 3 kali, evaluasi pertama adalah menunjukkan kepada karyawan EDP Keuangan bagaimana aplikasi bekerja. Evaluasi kedua dilakukan penambahan fitur untuk user yang memiliki hak akses sebagai administrator agar dapat melakukan posting pengumuman, dan setiap pesan yang masuk mendapatkan notifikasi. Evaluasi ketiga dilakukan perbaikan beberapa fungsi yang masih memiliki bug di dalamnya.
Kode Program 1. Konfigurasi NodeJS

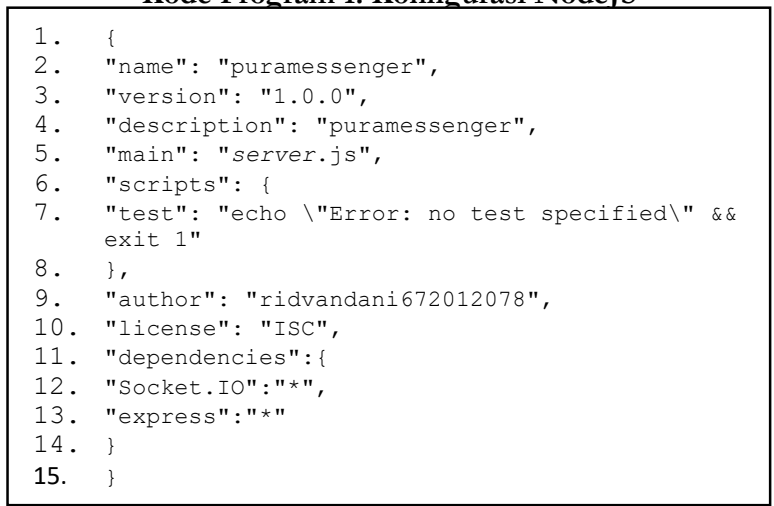

Kode Program 2. Konfigurasi Server

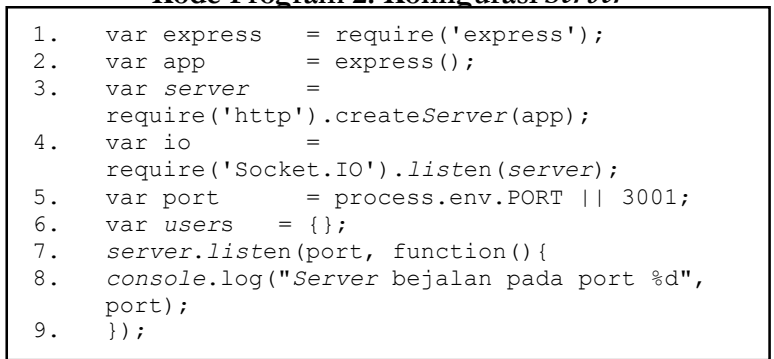

Kode Program 3. Konfigurasi Koneksi Database Framework CodeIgniter

\begin{tabular}{|c|c|c|}
\hline 1 . & $\$ d b$ ['default'] ['hostname'] & $=$ 'localhost $/ \mathrm{XE}$ '; \\
\hline 2 . & $\$ d b$ ['default'] ['username'] & $=$ 'pura_m'; \\
\hline 3. & $\$ d b[$ ['default'] ['password'] & $=$ 'pura-m'; \\
\hline 4. & $\$ d b$ ['default'] ['database'] & $=1 ' ;$ \\
\hline 5 . & $\$ d b$ ['default'] ['dbdriver'] & $=$ 'ocis'; \\
\hline 6 . & $\$ d b$ ['default'] ['dbprefix'] & $=1 ' ;$ \\
\hline 7. & $\$ d b$ ['default'] ['pconnect'] & $=$ TRUE; \\
\hline 8 . & $\$ d b$ ['default'] ['db_debug'] & $=$ TRUE; \\
\hline 9. & $\$ d b$ ['default'] ['cāche on'] & $=$ FALSE; \\
\hline 10. & $\$ d b$ ['default'] ['cachēir'] & $=1 ' ;$ \\
\hline 11 . & $\$ d b$ ['default'] ['char_set'] & $=$ 'utf8'; \\
\hline 12. & $\begin{array}{l}\text { \$db['default'] ['dbcollat'] } \\
\text { 'utf8_general_ci'; }\end{array}$ & $=$ \\
\hline 13. & $\$ d b$ ['default'] ['swap_pre'] & $=1 '$; \\
\hline 14 . & $\$ d b$ ['default'] ['autoinit'] & $=\mathrm{TRUE} ;$ \\
\hline & $\$ d b$ ['default'] ['stricton'] & $=$ FALSE \\
\hline
\end{tabular}

Kode Program 4. Konfigurasi Route Framework CodeIgniter

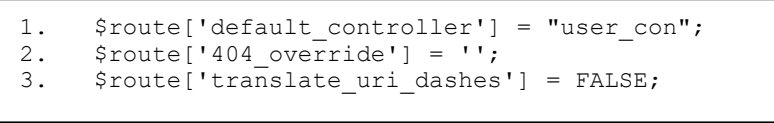

Kode Program 5. Menampilkan User yang Online atau Offline

\begin{tabular}{|c|c|}
\hline & \\
\hline 1. & function cek userlist() \{ \\
\hline 2 . & $\$ . \operatorname{ajax}(\{-$ \\
\hline 3 . & url: "<?php echo \\
\hline & base_url('index.php/user_con/userList'); ?>", \\
\hline 4. & cachē: false, \\
\hline 5. & success: function(msg) \{ \\
\hline 6 . & \$('\#userList'). load("<?php echo \\
\hline 7. & base url('index.php/user con/userList'); ?>"); \\
\hline 8 . & \}) ) ; \\
\hline 9 . & var waktu = setTimeout ("cek_userlist()", \\
\hline 10 . & \} \\
\hline
\end{tabular}




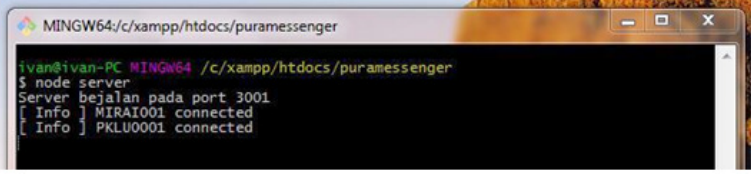

Gambar 7. Respon Server Ketika User Log in

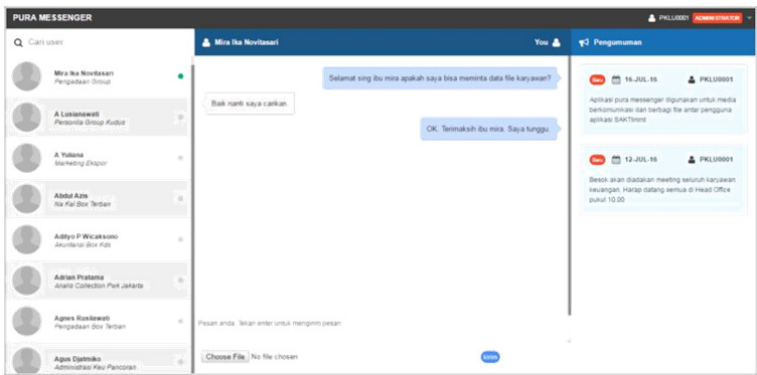

Gambar 8. Halaman Utama
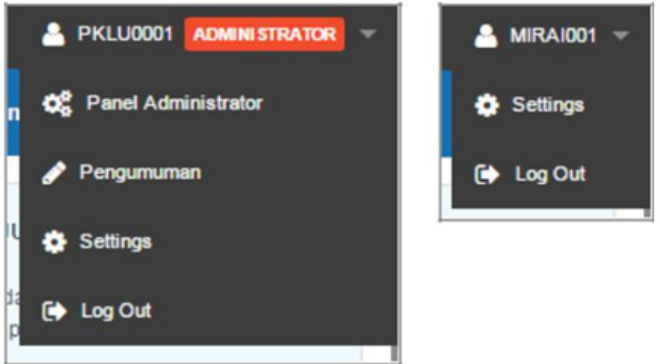

Gambar 9. Perbedaan Hak Akses Adminstrator dan User Biasa

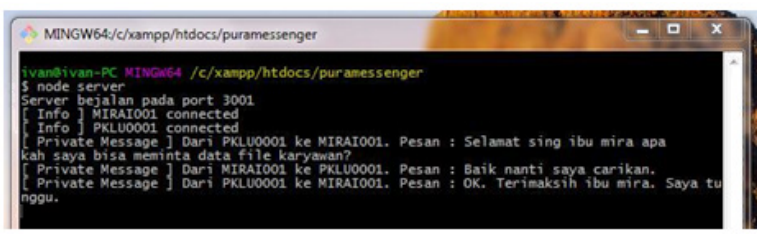

Gambar 10. Respon Server Ketika User Mengirim Pesan

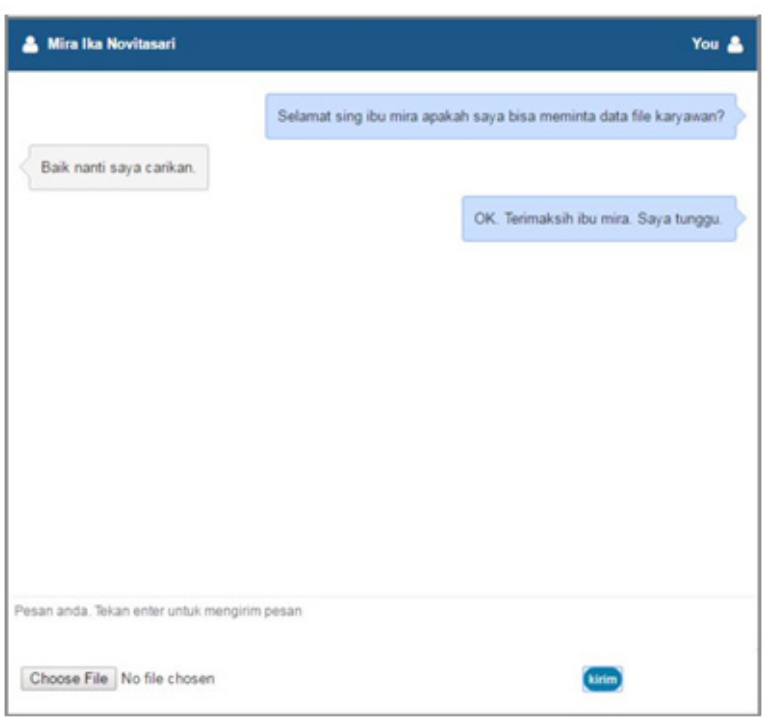

Gambar 11. Proses Chatting

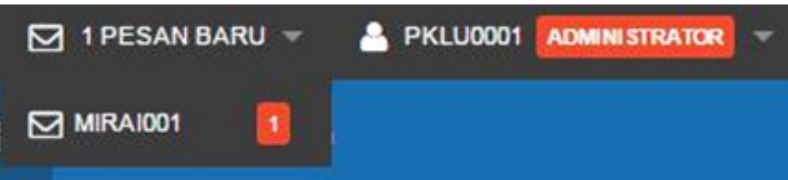

Gambar 12. Notifikasi Pesan yang Belum Dibaca

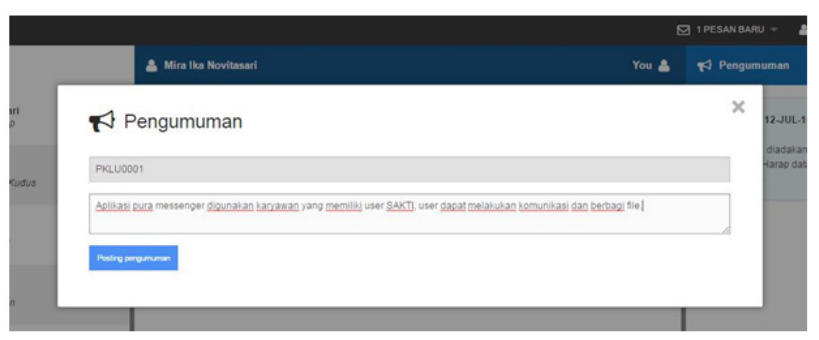

Gambar 13. Form Posting Pengumuman

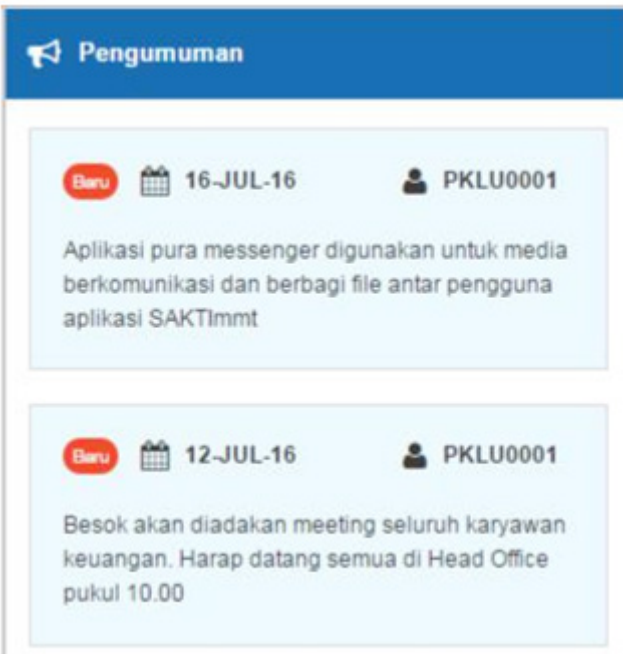

Gambar 14. Daftar Pengumuman
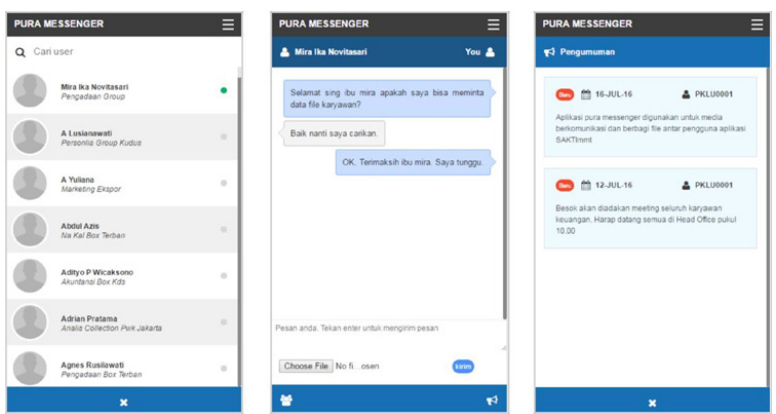

Gambar 15. Tampilan Responsive

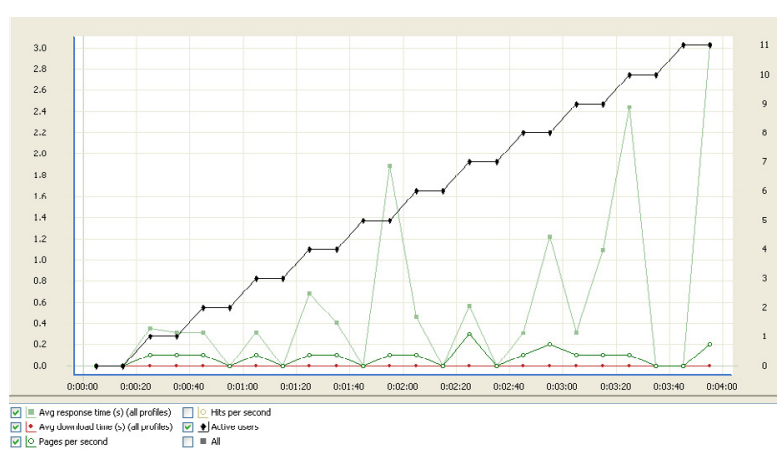

Gambar 16. Grafik Performance Aplikasi 


\section{Kode Program 6. Mengirim Pesan Melalui Socket}

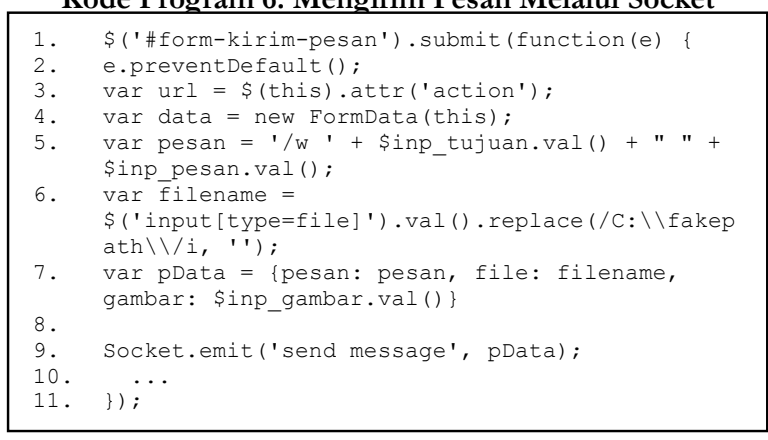

Kode Program 7. Media Query

1. @media (max-width: 700px) \{
2. .userListContainer \{display: none;
3. . announcementContainer \{display: none;
4. . chatbox \{height: $67 \%$ !important; \}
5. $\quad$ S

\section{Hasil dan Pembahasan}

Sebelum melakukan pengkodean. Hal pertama yang harus dilakukan adalah meng-install NodeJS. Tujuan dari intalasi NodeJS karena Socket.IO berjalan di atas NodeJS sebagai modul. Kemudian dilakukan inisialisasi project NodeJS dengan perintah npm init. Perintah ini akan menghasilkan file package.json yang terlihat pada Kode Program 1.

Kode Program 1 menujukkan deskripsi mengenai aplikasi yang dibuat. Kemudian melakukan penambahan dependencies untuk menambahkan Socket.IO dan Express. Setelah konfigurasi package.json, selanjutnya penginstallan Socket.IO dan Express dengan menjalankan perintah npm install pada command line. Setelah proses instalasi, selanjutnya membuatan server untuk aplikasi chatting yang ditunjukkan pada Kode Program 2.

Kode Program 2 menunjukkan inisialisasi Socket dan port. Pada baris 5 diinisialisasikan bahwa aplikasi chatting akan berjalan pada port 3001. Selanjutnya dilakukan konfigurasi pada Framework CodeIgniter agar aplikasi dapat terhubung dengan database yang ditunjukkan pada Kode Program 3.

Kode Program 3 menunjukan konfigurasi database yang berisi hostname, username, password, dan driver. Pada penelitian ini database yang digunakan adalah Oracle, maka driver yang digunakan adalah OCI8. Sedangkan untuk pengaturan route terlihat pada Kode Program 4.

Kode Program 4 menunjukkan controller mana yang akan dipanggil pertama kali saat aplikasi dijalankan. Pengubahan dilakukan pada baris 1 yaitu saat aplikasi dijalankan akan memanggil kelas controller user_con yang mengarah pada halaman log in. Pada halaman $\log$ in terdapat dua text field dan satu tombol. Text field pertama adalah tempat user untuk memasukkan user id user. Text field kedua adalah tempat user memasukkan password, dan tombol log in yang digunakan untuk memproses inputan dari user. Username dan password kemudian diproses untuk dilakukan pengecekan ke database. Apabila username dan password tidak terdapat dalam database, akan kembali ke halaman $\log$ in. Jika cocok akan maka user berhasil $\log$ in. Gambar 7 adalah respons server ketika ada user yang $\log$ in. Gambar 8 merupakan halaman yang akan muncul ketika user berhasil $\log$ in.

Gambar 8 menunjukkan halaman yang ditampilkan ketika user berhasil log in. Pada bagian header sebelah kanan terdapat menu untuk user. User dibagi menjadi 2 hak akses dengan menu yang berbeda. Hak akses yang pertama adalah adminstrator dan hak akses yang kedua adalah user biasa. Perbedaan menu dapat dilihat pada Gambar 9.

Gambar 9 menunjukkan perbedaan hak akses pada tiap-tiap user. User yang mendapat hak akses sebagai adminstrator terdapat label "administrator" sedangkan untuk user yang tidak mendapat hak akses administrator tidak terdapat label "administrator". User yang mendapat hak administrator terdapat menu panel administrator, pengumuman, settings, dan log out. Sedangkan user biasa hanya terdapat menu settings dan log out. Kedua hak akses tersebut bisa melakukan chatting dengan sesama user. Pada bagian di bawah header dibagi lagi menjadi 3 bagian yaitu bagian sebelah kiri untuk menampilkan user yang online maupun yang sedang offline. Bagian tengah untuk melakukan chatting, dan bagian kanan untuk menampilkan pengumuman. Untuk menampilkan user yang sedang online maupun offline aplikasi akan mereload secara berkala halaman userlist.

Kode Program 5 menunjukkan fungsi untuk menampilkan user yang online maupun offline dengan memanfaatkan Jquery Ajax, setiap 10000 millisecond class controller userList akan direload secara terus menerus tanpa merefresh keseluruhan halaman. Proses chatting pada penelitian ini memanfaatkan library Javascript Socket. IO. Penggunaan Socket.IO memungkinkan komunikasi secara realtime antara client dan server. Socket.IO berjalan pada web browser dan berjalan pada server. Kode Program 6 merupakan fungsi pada sisi client untuk mengirimkan data dari client ke server.

Kode Program 6 menunjukkan fungsi untuk mengirimkan data dari client ke server. Data yang diinputkan akan menjadi parameter pada fungsi 'send message' pada komputer client dan diterima oleh server.

Gambar 10 menunjukkan aktivitas server. Pesan yang masuk akan ditampilkan ke dalam console. Server mengirim nilai pengembalian data pada client dalam fungsi 'whisper' dan "kirim". Gambar 11 merupakan hasil data yang ditampilkan di web browser. Gambar 12 merupakan notifikasi ketika ada pesan yang belum dibaca.

Gambar 12 menunjukkan notifikasi pesan yang belum dibaca. Ketika ada pesan yang baru saja masuk atau pesan yang belum dibaca, pada header akan muncul notifikasi yang berisi jumlah pesan dan siapa pengirim pesan tersebut. User dengan hak akses administrator juga bisa melakukan posting pengumuman. Posting pengumuman juga dilakukan melalui Socket.

Gambar 13 menunjukkan form untuk menulis pengumuman. Data inputan akan dikirimkan ke server. Kemudian server mengolah data dan mengirimkan kembali ke client untuk ditampilkan yang terlihat pada Gambar 14.

Aplikasi chatting yang dibangun dapat menyesuaikan dengan resolusi layar ketika aplikasi diakses dengan memanfaatkan Framework Foundation. Pemanfaatan Framework Foundation aplikasi web akan menjadi responsive. 
Grid dalam framework. Foundation digunakan untuk mengaktifkan fitur responsive. Maksimum penggunaan grid pada Framework Foundation adalah 12 kolom. Grid dikelompokkan menjadi 3 properti yaitu small, medium, large. Properti small digunakan untuk menyesuaikan resolusi layar yang kecil, properti medium digunakan untuk menyesuaikan resolusi layar yang lebih besar dari properti small dan properti large untuk resolusi layar yang lebih besar lagi. Kode Program 7 menunjukkan pengaturan media query yang digunakan untuk menampilkan layout yang berbeda berdasarkan media yang digunakan.

Gambar 15 menunjukkan tampilan aplikasi ketika diakses pada resolusi layar yang lebih kecil. Dilakukan penambahan menu pada sisi bawah layar untuk mengakses menu melihat daftar user dan melihat pengumuman.

Pengujian sistem dilakukan untuk mencari kesalahan pada aplikasi chatting yang dibuat. Pengujian dilakukan untuk mengetahui apakah aplikasi yang sudah dibuat berjalan dengan baik dan sesuai dengan kebutuhan user. Pengujian alpha menggunakan metode blackbox yaitu pengujian fungsi-fungsi aplikasi secara langsung tanpa memperhatikan alur eksekusi program. Pengujian ini dilakukan dengan memeriksa setiap fitur aplikasi. Berdasarkan pengujian yang dilakukan pada aplikasi chatting, setiap fungsi dapat berjalan dengan baik, termasuk dapat mengirimkan dan menerima file attacthment dengan ukuran maksimum 25 MB. Berdasarkan hal ini, maka disimpulkan bahwa aplikasi ini berfungsi dengan baik dan sesuai yang diharapkan.

Pengujian lainnya juga dilakukan untuk menguji performa aplikasi chatting ini ketika digunakan oleh banyak user. Pengujian dilakukan dengan bantuan aplikasi Web Application Testing (WAPT), yaitu melibatkan 110 user. Hasil pengujian ditunjukkan oleh Gambar 16.

Berdasarkan grafik pada Gambar 16, dapat dijelaskan tentang performance aplikasi yang meliputi waktu response yang dibutuhkan oleh seorang user untuk menunggu response dari server, waktu download yang dibutuhkan oleh user dan banyaknya halaman web yang dapat dieksekusi tiap detik. Hasil pada grafik menunjukkan bahwa waktu response aplikasi cenderung tidak stabil. Karena pada interval waktu tertentu terjadi waktu response yang singkat yaitu 0 detik dan kadang terjadi waktu response yang cenderung lama yaitu 3.03 detik. Dalam analisis waktu response terdapat 3 (tiga) batasan, yaitu waktu response 0.1 detik merupakan batas ideal bagi user dalam menunggu response dari server, 1.0 detik merupakan batas yang masih bisa ditoleransi dan untuk batas 10 detik merupakan batas yang tidak dapat ditoleransi lagi, karena menurut survey waktu response yang memasuki detik ke 8.0 akan membuat user meninggalkan sistem. Dari grafik dapat disimpulkan bahwa waktu response masih dapat ditoleransi, karena berada dalam batas 0.0 - 3.0 detik.

Download time yang dimaksud di sini adalah waktu yang dibutuhkan pada saat user melihat web title (pada browser title bar) hingga user dapat melihat halaman web yang meliputi frame, tabel dan HTML text. Dari grafik pada Gambar 16 terlihat bahwa download time dapat dikatakan stabil (waktu download tidak berubah untuk tiap periode waktu) dan singkat (waktu download hanya 0 detik).

Pages per second yang dimaksud adalah banyaknya halaman web yang dapat dieksekusi tiap detik. Hal ini terlihat pada grafik pada Gambar 16 di mana untuk tiap interval waktu tertentu tidak terjadi perubahan pages per second yang besar. Didapatkan 0.1 halaman tiap detik (paling sedikit) dan 0.3 halaman tiap detik (paling banyak).

Pengujian beta dilakukan dengan melakukan presentasi dengan EDP Keuangan. Presentasi dilakukan dengan melakukan demo program yang telah di-upload ke server untuk mengetahui apakah aplikasi chatting berfungsi dengan baik dan sesuai kebutuhan pengguna. Berdasarkan hasil presentasi dengan karyawan EDP Keuangan, aplikasi berfungi dengan baik dan sesuai dengan kebutuhan pengguna.

\section{Kesimpulan}

Berdasarkan penelitian yang telah dilakukan maka dapat diambil kesimpulan bahwa pembuatan aplikasi chatting dapat dibuat dengan menggunakan Framework CodeIgniter, Socket.IO dan Framework Foundation. Pemanfaatan Framework CodeIgniter dapat diterapkan konsep MVC (Model View Controller) sehingga penulisan kode menjadi lebih terstruktur dan terorganisir. Pemanfaatan Socket.IO cocok untuk pembuatan aplikasi realtime seperti aplikasi chatting dan Framework Foundation membuat tampilan aplikasi menjadi responsive yang dapat menyesuaikan diberbagai resolusi layar.

Berdasarkan hasil pengujian, aplikasi chatting dapat membantu karyawan EDP Keuangan atau user lainnya untuk berkomunikasi, attach file dengan ukuran maksimum $25 \mathrm{MB}$, dan menyebarkan informasi jika sewaktu-waktu terjadi penambahan atau perubahan program yang dikembangkan oleh karyawan EDP Keuangan. Spesifikasi hardware maupun software aplikasi chatting ini tergolong aplikasi yang ringan karena merupakan aplikasi berbasis web, user hanya membutuhkan web browser kemudian mengakses aplikasi chatting yang sudah diupload ke server dan dengan memanfaatkan jaringan lokal maka untuk mengakses aplikasi chatting tidak membutuhkan koneksi internet.

Saran pengembangan yang dapat dilakukan adalah dengan menambahkan fitur keamanan pada aplikasi chatting. Fitur keamanan ini digunakan untuk mengenkripsi pesan chat yang dikirimkan. Aplikasi chatting juga bisa dikembangkan untuk versi aplikasi mobile yang tersinkronisasi ke aplikasi chatting web ini, sehingga user experience menjadi lebih baik.

\section{Daftar Pustaka}

[1] M. Z. Teddy, dan D. W. Surya, "Aplikasi Chat pada Handphone dan Komputer dengan Media Bluetooth (Bluetooth Chat)," Jurnal Teknologi Informasi - Aiti, vol. 4, no. 1, pp. 60-74, 2009.

[2] S. Roni, dan S. Edhy, "Membangun Aplikasi Chatting Berbasis Multiuser," Jurnal Dasi, vol. 10, no. 1, pp.3-22, 2009.

[3] E. Sularso, W. S. Raharjo, \& Y. Lukito, "Implementsi Algoritma RijnDeal 128 pada Aplikasi Chatting Berbasis HTML WebSocket," Jurnal Infromatika, vol. 10, no. 2, pp. 66-79, 2014. 
[4] Priyanto, D. Mahir Komputer Tanpa Kursus. Belajar Mudah Internet. Yogyakarta: MediaKom, 2009.

[5] Wardana. Menjadi Master PHP dengen Framework CodeIgniter. Jakarta: Elex Media Komputindo, 2010.

[6] Anonymous. Nodesource. [Online], https:// nodesource.com/blog/understanding-socketio/, tanggal akses 6 Juli 2016.

[7] Anonymous. Foundation Zurb. [Online], http:// foundation.zurb.com/learn/why-foundation. html/, tanggal akses 6 Juli 2016.
[8] Nugroho, A. Mengembangkan Aplikasi Basis Data Menggunakan C\# dan SQL Server. Yogyakarta: Andi, 2010.

[9] Hasibuan, Z. A. Metodologi Penelitian Pada Bidang Ilmu Komputer dan Teknologi Informasi: Konsep, Teknik, dan Aplikasi. Jakarta: Ilmu Komputer Univesitas Indonesia, 2007.

[10] Pressman, R. S. Software Engineering: A Practitioner's Approach, 2001. 